\title{
LITERATURA, ABERTURAS, VARIAÇÕES COM GÊNEROS E SEXUALIDADES: MANIFESTO POR UMA EDUCAÇÃO EM BIOLOGIA MENOR ${ }^{1}$
}

\author{
LITERATURE, OPENINGS, VARIANTIONS WITH GENDER AND SEXUALITY: \\ MANIFEST FOR AN EDUCATION IN MINOR BIOLOGY
}

\author{
Sandro Prado Santos ${ }^{2}$ \\ Matheus Moura Martins ${ }^{3}$ \\ Fabrício Aparecido Gomes da Silva ${ }^{4}$
}

\begin{abstract}
Resumo: A proposta é apresentar possibilidades de leituras dos territórios da educação em biologia atravessadas com a estética poética de Manoel de Barros, com a criação dos conceitos de educação em biologia menor e maior a partir das composições da obra "Kafka: por uma literatura menor" (DELEUZE; GUATTARI, 2015), com os deslocamentos do conceito "menor" no campo educacional (GALLO, 2016), bem como a insurgência de uma experimentação-manifesto com usos menores na educação em biologia. Essas alianças fizeram re-nascer outros encontros, sensações, expressões, inter(in)venções e políticas com a educação em biologia, nos engajando e conjugando com processos que minoram os modos majoritários das discussões de gênero e sexualidade que circulam nesse campo. Com isso, esperamos que esse texto-máquina instigue leitores/as a se debruçarem, também, nas travessuras de visibilizar outras linhas que fissuram tentativas totalitárias de uso maior nos territórios da educação em biologia.
\end{abstract}

Palavras-chave: Educação em biologia menor; territorialidades; filosofia da diferença.

Abstract: The proposal is to present possibilities of reading the territories of biology education crossed with the poetic esthetics of Manoel de Barros, with the creation of the concepts of education in minor and greater biology from the compositions of the work "Kafka: por uma literatura menor" (DELEUZE; GUATTARI, 2015), with the displacements of the "minor" concept in the educational field (GALLO, 2016), as well as the insurgency of a manifest experimentation with minor uses in biology education. These alliances reborn other encounters, sensations, expressions, inter(in)ventions and policies with biology education engaging and combining with processes that reduce the majority modes of discussions of gender and sexuality that circulate in this field. With this, we hope that this text-machine will also instruct readers to address the in the antics of making other lines make visible that crack totalitarian attempts of greater use in the territories of biology education.

Keywords: Education in minor biology; territorialities; philosophy of difference.

\section{Linhas insurgentes...}

A ideia da escrita desse texto surge a - com as filosofias da diferença (DELEUZE; GUATTARI, 2015) e as irrupções poéticas de Manoel de Barros (BARROS, 2010; 2016). Essas nos mobilizaram variações e aberturas dos/com processos educativos em biologia e nos implicaram com as complexas configurações territoriais das práticas formativas, dos discursos

\footnotetext{
${ }^{1}$ Parte desse texto foi apresentado na seção de comunicações orais "Variações em Educação" no III Colóquio Variações Deleuzianas: Corpo entre filosofia e arte e educação. Um evento on-line realizado nos dias 23 , 24 e 25 de novembro/2020. Universidade Federal do Pará.

${ }^{2}$ Universidade Federal de Uberlândia, Uberlândia, MG, Brasil.

${ }^{3}$ Universidade Federal de Uberlândia, Uberlândia, MG, Brasil.

${ }^{4}$ Universidade Federal de Uberlândia, Uberlândia, MG, Brasil.
} 
e valores acerca dos corpos, gêneros e sexualidades, que, historicamente, ocupam, atravessam, constituem, agenciam e disputam os campos epistemológicos, pedagógicos, didáticos e curriculares da educação em biologia (SANTOS, 2018).

Nessa seara, destacamos as alianças e os encontros entre as experiências de pessoas trans com a educação em biologia, circunstâncias em que outras cartografias foram acionadas para além de significados universais, estáticos e exatos de gêneros e sexualidades (SANTOS, 2018). Desse modo, os encontros e as insurgências de histórias, práticas, línguas e povos que atravessam a educação em biologia por meio de "[..] uma rede complexa de práticas semióticasmateriais [...]" (HARAWAY, 2017, p. 51) criam territorialidades. Assim, se há nos territórios uma produção de segmentações, normatizações, regulações, pautas curriculares e controles aos gêneros e sexualidades, como por exemplo, ao que tem sido estabelecido pela Base Nacional Comum Curricular (BNCC), há, também re-existências que desejam e produzem vibrações territoriais, fissuras, (des)alinhamentos e deslocamentos no que se vê e o no que se diz aos/dos gêneros e sexualidades nos processos educativos estabelecidos, possibilitando movimentos de criações e experimentações (SANTOS, 2018). Encontros e insurgências que nos provocaram a pensar aberturas de leituras e variações com à educação em biologia como um "[...] território político, ético e estético [...]" (PARAÍSO; CALDEIRA, 2018, p. 14).

Nesse contexto, tais atravessamentos nos provocaram alianças com: a) as potências e deslocamentos poéticos com Manoel de Barros, especialmente, um mundo pequeno, das coisas menores, dos restos, de uma gramática expositiva do chão, à primeira vista desimportantes, rasteiras, sobre nada, insignificantes, ínfimas. Olhares comungantes e oblíquos para o ser menor das coisas que fez com que a sua literatura nos atravessasse com olhares outros, expandindo as imaginações e as possibilidades de re-arranjos territoriais da educação em biologia; b) a obra "Kafka: por uma literatura menor" (DELEUZE; GUATTARI, 2015) que se põem a pensar que uma língua maior é sempre acompanhada por linhas de variações contínuas, por seus usos menores; e, c) os deslocamentos do conceito de menor no campo educacional (GALLO, 2016).

A aposta na educação menor está no seu potencial de "[...] manutenção de seu caráter minoritário [...]", bem como em sua "[...] capacidade de não se render aos mecanismos de controle [...]", funcionando como "[...] máquina de resistência” (GALLO, 2016, p. 70). Com isso, esse conceito tem sido estudado e mobilizado em múltiplas dimensões de práticas educativas, despertando, também, perspectivas e problemas investigativos outros para o pensar e o fazer de pesquisas na área de educação. O disparar do conceito de menor no campo educacional, nos mobilizou um pensar outro com as práticas educativas na educação em biologia. Nesse contexto, deslocamos e experimentamos o conceito para pensar as discussões de gênero e sexualidade na educação em biologia, sobretudo nas situações em que temos, concretamente, o uso do Livro Didático (LD) de Biologia no fazer pedagógico contemporâneo (SANTOS; SILVA; MARTINS, 2021). Assim, agenciamos os conceitos de biologia maior e de biologia menor como dispositivos para pensarmos as discussões de gênero e sexualidade.

Nesse sentido, a proposta aqui é apresentar as possibilidades de leituras dos territórios da educação em biologia atravessadas com a estética poética de Manoel de Barros e com a criação dos conceitos de educação em biologia menor e maior, bem como a insurgência de uma experimentação-manifesto a partir da perspectiva de usos menores com a educação em biologia.

\section{Educação em biologia e territorialidades e gêneros e sexualidades e...}

A leitura da bióloga feminista Donna Haraway (2017) enreda a biologia numa complexa rede de signos linguísticos que organizam e atravessam uma grande parte da vida com relações de poderes-saberes, educação, produções econômico-culturais, técnicas, discursos, 
histórias, práticas semióticas-materiais, línguas, povos e... e.... ${ }^{5}$ Tais elementos que convergem aos interesses de Deleuze e Guattari (2015), criam territorialidades, ao pensarem e comporem com as potências do campo da literatura, sobretudo a obra de $\mathrm{Kafka}^{6}$, com atributos linguísticos, políticos e coletivos.

[...] as línguas podem ser consideradas maiores ou menores: maiores quando têm uma forte estrutura homogênea e constantes ou universais de natureza fonológica, sintática ou semântica, o que as faz línguas do poder; menores quando só comportam um mínimo de constantes e de homogeneidade estrutural. [...] maior e menor qualificam menos línguas diferentes do que usos diferentes da mesma língua [...] toda língua maior é marcada por linhas de variação contínua, quer dizer, por usos menores (DELEUZE, 2010, p. 14).

Nesse sentido, assim como a literatura, consideramos que a Educação em Biologia, também, cria suas territorialidades. Foram as carto-grafias e alianças com as pessoas trans que fizeram insurgir as pistas, nuances e movimentos no mapeamento supostamente estático dos territórios, ora povoados de discursos exatos de corpos, gêneros e sexualidades ora atravessados por torções e deslocamentos de sentidos (SANTOS, 2018).

Nessa seara, consideramos os gêneros e sexualidades como constitutivos e constituintes da configuração territorial das práticas educativas, curriculares e formativas na Educação em Biologia. Os ditos e vistos desses dispositivos (FOUCAULT, 1979) ecoam e funcionam desde dentro na territorialização e organização do jogo que está na ordem das coisas da educação em Biologia, (RANNIERY; LEMOS, 2018), produzindo-a enquanto territórios que oscilam entre dois planos a partir dos movimentos dos gêneros e sexualidades: de um lado, as superfícies de estratificação, normalizações e (órgão)nização, e, por outro, o plano no qual eles resistem, insistem, conectam, rizomatizam, criam e fluem como campos intensivos. Planos que atuam, operam, funcionam e coexistem ao mesmo tempo nas superfícies territoriais.

Com isso, temos pensado a educação em biologia como um "'[...] território político, ético e estético incontrolável que, se é usada para regular e ordenar, pode também ser território de escapes de todos os tipos com [...] trajetos grávidos de esperança [...]" (PARAÍSO; CALDEIRA, 2018, p. 14).

Com isso, salientamos que um pensar os trajetos grávidos de esperança de "novos mundos" nos territórios da educação em biologia, também, nos chegou pelos poemas de Manoel de Barros. Nesse sentido, as inspirações poéticas pantaneira manoelinas fizeram renascer e re-criar um encantamento pelas composições com outros encontros, outras sensações, expressões, inter(in)venções e outras políticas com a educação em biologia, nos engajando e conjugando com processos que minoram os modos majoritários das discussões de gênero e sexualidade que circulam nesse campo.

\footnotetext{
5 A biologia não é o próprio corpo, mas um discurso sobre o corpo. 'Minha biologia' [...] não é a própria suculenta carne mortal, mas um signo linguístico para uma estrutura complexa de crença e prática por meio da qual [...] organizamos uma grande parte da vida. A biologia não é também um discurso universal livre da cultura, pois ela tem considerável poder cultural, econômico e técnico para estabelecer o que será considerado como natureza por todas as partes do planeta Terra. A biologia não é um discurso de todo mundo sobre a carne, vida e natureza humana, animal e vegetal; na verdade, 'carne', 'vida' e 'natureza' não estão menos enraizadas em histórias, práticas, línguas e povos do que a própria 'biologia'. Ela é, ao invés disso, uma rede complexa de práticas semióticas-materiais [...] (HARAWAY, 2017, p. 51).

${ }^{6} \mathrm{Na}$ obra "Kafka: por uma literatura menor", Deleuze e Guattari (2015) advogam uma perspectiva nova da literatura. Eles a propõem como uma trincheira, um espaço de habitação, uma máquina política e experimental que transforma nossas experiências, nos lançando (o/a leitor/a e a literatura) a caminhos outros.
} 


\section{Irrupções poéticas de Manoel de Barros na educação em biologia}

línguas

contenho vocação pra não saber línguas cultas. sou capaz de entender as abelhas do que alemão. eu domino os instintos primitivos.

a única língua que estudei com força foi a portuguesa. estudei-a com força para poder errá-la ao dente.

a língua dos índios guatós é múrmura: é como se ao dentro de suas palavras corresse um rio entre pedras.

a língua dos guaranis é gárrula: para eles é muito mais importante o rumor das palavras do que o sentido que elas tenham. usam trinados até na dor.

na língua dos guanás há sempre uma sombra do charco em que vivem. mas é língua matinal. há nos seus termos réstias de um sol infantil.

in: manoel de barros. poesia completa. são paulo: leya, 2010, p. 381-382.

Borboletas de tarjas vermelhas $e$ um rio que flui entre dois lagartos $e$ a criança que escuta a cor dos pássaros $e$ araticuns maduros $e$ tartarugas $e$ protocolo vegetal $e$ cobra de vidro $e$ lagartos $e$ formigas $e$ árvores $e$ a máquina que engravida pelo vento $e$ moscas $e$ como pegar na voz de um peixe $e$ sotaques das águas $e$ escutar os perfumes dos rios $e$ insetos $e$ pedras $e$ jeito de falar pantaneiro $e$ o mato $e$ sabedoria vegetal $e$ mineral $e$ pessoas pertencidas ao abandono $e$ coisinhas do chão $e$ lobos $e$ transfusão da natureza $e$ comunhão com ela $e$ uma sinfonia da natureza; compõem a poesia de Manoel de Barros, nos conduzindo ao mundo da biologia, especialmente, um mundo pequeno, das coisas menores, dos restos, de uma gramática expositiva do chão, à primeira vista desimportantes, rasteiras, sobre nada, insignificantes, ínfimas. No entanto, é esse olhar comungante e oblíquo para o ser menor das coisas que faz com que sua literatura atice nossos olhares, expande as imaginações e nos redimensiona.

Nesse sentido, os poemas produzidos por Manoel de Barros, um dos poetas brasileiros mato-grossense mais importantes de nossa conjuntura, nos parecem estar justamente engajados num tipo de literatura agenciada com um (des)fazer maquínico de certos territórios existenciais, produzindo novos mundos, bem como um espaço fértil de afetar com possibilidades de uma minoração, delírio, devir, desvios de uma língua maior. Com eles, experimentamos! Os seus funcionamentos nos lançaram em caminhos outros para pensar a educação em biologia que, 
também, é atravessada por histórias, práticas, línguas e povos (HARAWAY, 2017). Vejamos, a seguir, essas maquinações ${ }^{7}$ !

Descobri aos 13 anos que o que me dava prazer nas

leituras não era a beleza das frases, mas a doença delas.

Comuniquei ao Padre Ezequiel, um meu Preceptor, esse gosto esquisito.

Eu pensava que fosse um sujeito escaleno.

- Gostar de fazer defeitos na frase é muito saudável, o Padre me disse.

Ele fez um limpamento em meus receios.

O Padre falou ainda: Manoel, isso não é doença, pode muito que você carregue para o resto da vida um certo gosto por nadas...

E se riu.

Você não é de bugre? - ele continuou.

Que sim, eu respondi.

Veja que bugre só pega por desvios, não anda em estradas -

Pois é nos desvios que encontra as melhores surpresas e os ariticuns maduros.

Há que apenas saber errar bem o seu idioma.

Esse Padre Ezequiel foi o meu primeiro professor de agramática.

BARROS, Manoel. O livro das ignorãças. 1. a edição. Rio de Janeiro: Alfaguara, 2016.

Nesse poema ${ }^{8}$, Manoel de Barros literalmente nos interpela com as potencialidades e as oportunidades da linguagem em fazer fugir um modo de dizer expectável, fazendo insurgir uma série de outros elementos "menos importantes", "esquisitos", "sujeito escaleno", "desviantes" que nas leituras que andam pelas "estradas" e pela "beleza das frases" não aparecem. Um exercício micro-revolucionário que faz aparecer outro conjunto de relações que podemos estabelecer com a linguagem e que disputam (in)visibilidades, pois está subjugado pelas relações de poder. Manoel marca e nos lança num movimento de limpamento dos elementos de poder do idioma, da leitura, da gramática e das frases, com os seus desvios nos apresenta um mundo pequeno da linguagem em que encontramos as melhores surpresas e des-territorializações que abalam (com uma série de variações possíveis) os modos com os quais nós fomos subjetivados com a linguagem.

A literatura de Manoel de Barros “[...] mestre da revelação do que até então não existia e se vê capturado no vocábulo [...]" amplia a crítica aos elementos presentes na língua, nos gostos, na vida, que representam e decalcam um expectável, para atingir uma variação que perturba e faz fugir o modo de dizer de "codificações prévias". (BARROS, 2016, p. 7-8).

No percurso pelas produções de Manoel de Barros, um outro encontro foi com o poema " $O$ apanhador de desperdícios". Nele há um convite de um privilégio de acon-teçimentos com o menor.

\footnotetext{
${ }^{7}$ Em “Crítica e Clínica”, Deleuze (2011) reforça a produção maquínica da literatura (uma máquina de guerra, uma experimentação política) como um "[...] devir-outro da língua, uma minoração da língua maior, um delírio que a arrasta, uma linha de feitiçaria que foge ao sistema dominante [...] a língua é tomada por um delírio que a faz precisamente sair de seus próprios sulcos [...] o escritor vê e ouve nos interstícios da linguagem, nos desvios da linguagem" (p. 16), implicada como uma escrita que "[...] consiste em inventar um povo que falta. Compete à função fabuladora inventar um povo [...]" uma "[...] enunciação coletiva de um povo menor, ou de todos os povos menores, que só encontram expressão no escritor e através dele" (p. 14).

${ }^{8}$ Poema VII da $3^{\text {a }}$ parte - Mundo pequeno, da obra "Livro das ignorãças".
} 


\section{O APANHADOR DE DESPERDÍCIOS}

Uso a palavra para compor meus silêncios. Não gosto das palavras fatigadas de informar.

Dou mais respeito

às que vivem de barriga no chão tipo água pedra sapo.

Entendo bem o sotaque das águas.

Dou respeito às coisas desimportantes e aos seres desimportantes.

Prezo insetos mais que aviões.

Prezo a velocidade

das tartarugas mais que as dos mísseis.

Tenho em mim esse atraso de nascença.

Eu fui aparelhado para gostar de passarinhos.

Tenho abundância de ser feliz por isso.

Meu quintal é maior do que o mundo.

Sou um apanhador de desperdícios:

Amo os restos como as boas moscas.

Queria que a minha voz tivesse um formato de canto.

Porque eu não sou da informática: eu sou da invencionática.

Só uso a palavra para compor os meus silêncios.

Nele, encontramos um uso poético da língua, dos gostos, da voz, dos gestos, dos movimentos, minorando um uso maior de cada um desses elementos para fazer aparecer um momento de multiplicidade de forças minoritárias e de diferenciação que implicam em uma "invencionática" de outros mundos, e, que daqui podemos extrair micropolíticas que interessam na constituição de sensibilidades outras.

Portanto, a inspiração poética pantaneira de Manoel de Barros foi uma força-motriz que nos trouxe pistas para pensarmos "novos mundos" nos territórios da educação em biologia. $\mathrm{O}$ poema a seguir mapeia a composição do ambiente, optando por senti-lo na co-existência de significados e de potencialidades de um pensamento insurgente, importando mais com as intensidades dessas últimas.

Aprendo com abelhas do que com aeroplanos.

É um olhar para baixo que eu nasci tendo.

É um olhar para o ser menor, para o insignificante que eu me criei tendo.

O ser que na sociedade é chutado como uma barata - cresce de importância para o meu olho.

Ainda não entendi por que herdei esse olhar para baixo.

Sempre imagino que venha de ancestralidades machucadas.

Fui criado no mato e aprendi a gostar das coisinhas do chão -

Antes que das coisas celestiais.

Pessoas pertencidas de abandono me comovem: tanto quanto as soberbas coisas ínfimas.

BARROS, Manoel de. Retrato do artista quando coisa. Rio de Janeiro: Record, 1998.

O poema foi um disparador de processos criativos que insurgiram aos territórios da educação em biologia: Quais temáticas ou discussões tem sido/servido de abandono para a educação em biologia? O que esse poema e ideias nos lançam ao pensarmos a educação em biologia? Onde estariam "o ser menor", o insignificante, as coisas ínfimas, o olhar para baixo 
e a aprendizagem das coisinhas do chão nas produções curriculares da Biologia? Será que nossas aprendizagens apenas e para com os aeroplanos, com coisas celestiais (topos das ideias, modelo) não estariam prontas para retirar de nossas aulas de biologia, a importância da multiplicidade, da criação, das minoridades, e elevá-las ao mais próximo de uma universalidade celestial? $\mathrm{O}$ desconhecer do olhar para baixo, para as soberbas coisas ínfimas e a aprendizagem das coisinhas do chão nas produções curriculares de Biologia num estaria tentando evitar uma desterritorialização da lógica extremamente biológica da educação em biologia? E quem sabe, talvez tentando salvá-las de uma criação-experimentação de outras sub-versões?

Elas nos interpelaram olhares com a educação em biologia, arquitetando nos territórios muitas outras riquezas que estavam ali invisibilizadas, fazendo fugir o óbvio ou o expectável e surgir um modo de dizer outro, "[...] Fazer o desprezível ser prezado é coisa que me apraz [...]" (BARROS, 2016, p. 79) ${ }^{9}$. Assim, temos experimentado olhares ao menor, também, no campo da Educação em Biologia com os gêneros e sexualidades, possibilitando um pensar de uma educação em Biologia menor, um mundo pequeno ${ }^{10}$.

Fomos tomando gosto pelos nadas, pelos desvios, pelo insignificante e o desprezível, pelas coisas abandonadas e ínfimas das questões de gênero e sexualidade que são (in)visibilizadas nos territórios da educação em biologia, sempre numa aposta que tais (in)existências comunguem com/nos territórios, (n)uma didática da invenção ${ }^{11}$.

Nas composições e entrelaçamentos com tais produções, e, apesar de vivermos em uma educação em biologia em que somos assombrados pelos seus usos maiores que se julgam grandes e sabidos, aprendemos com os segredos e as surpresas dos desvios, das coisas ínfimas e do apequenar-se na gramática que encarnam no uso do menor e praticam o exercício de fazer delirar o regime discursivo da biologia, fazendo nascimentos de biologias outras que reinventam e ampliam outros modos de expressões de gêneros e sexualidades nos territórios da educação em biologia.

Nesse sentido, tais provocações poéticas manoelinas nos sensibilizaram olhares e experimentações conceituais para pensarmos as discussões de gênero e sexualidade na educação em biologia. Foram operações que nos abriram espaços para disparar os conceitos de educação em biologia maior e a educação em biologia menor como dispositivos para pensar as discussões de gênero e sexualidade nos territórios.

Desse modo, se a Educação em Biologia maior está implicada na produção de elementos de homogeneização, da binarização, da neutralidade, da representação, invariabilidade, estabilização, vontade de saber-poder, de uma totalidade orgânica, constâncias e universalizações, a educação em biologia menor nos apresenta como uma máquina de resistência e manifestação a tais usos.

\footnotetext{
${ }^{9}$ BARROS, Manoel. O livro das ignorãças. 1. ed. Rio de Janeiro: Alfaguara, 2016.

${ }^{10}$ BARROS, Manoel. O livro das ignorãças. 1. ed. Rio de Janeiro: Alfaguara, 2016.

${ }^{11}$ BARROS, Manoel. O livro das ignorãças. 1. ed. Rio de Janeiro: Alfaguara, 2016.
} 


\section{manifesto por uma educação em biologia menor ${ }^{12}$}

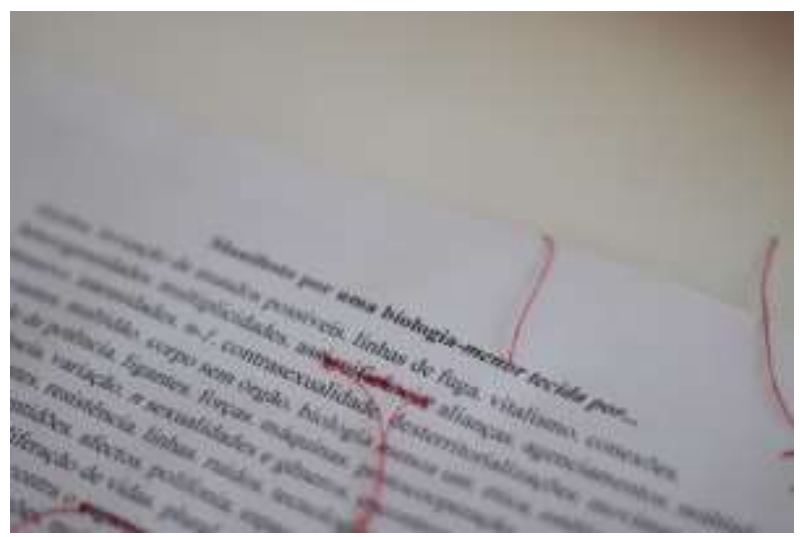

Figura 1: Manifesto - Foto-Autoria: Camila de Sousa Siqueira

"Você entrou, e isto é um manifesto que nos convoca para as possibilidades de uma educação em biologia menor. Já de aviso, aliamos aqui com a obra "Kafka: por uma literatura menor", que se põe a pensar que uma língua maior é sempre acompanhada por linhas de variações contínuas, por seus usos menores; e com os deslocamentos do conceito de menor no campo educacional, mobilizados pela Filosofia da Diferença de Gilles Deleuze e Félix Guattari e seus agenciamentos com os territórios da educação em Biologia” (SANTOS; MARTINS, 2020, p. 1).

rizoma. invenção-produção de mundos possíveis. linhas de fuga. vitalismo. conexões. heterogeneidades. multiplicidades. assignifieância. alianças. agenciamentos. múltiplo. intensivo. intensidades. $n$ - 1 . contrasexualidade. desterritorializações. movimento. desviantes. multidão. corpo sem órgão. biologia-1. ética, estética. política. vontade de potência. ligantes. forças. máquinas. protocooperação. criação. tecnologias de resistência. variação. $n$ sexualidades. gêneros. encontros. devires. sub-versões. fluxos. errantes. resistência. linhas. ruídos. tecnologias sócio-políticas. gagueiras. velocidades. lentidões. afectos. polifonia. espaços movediços. pensamento-outro. educ(ações). proliferação de vidas. plural. máquina de guerra. regimes de signos-corpos. contra o organismo. espaços porosos. heterotópico. fissuras. cartografias. composições. molecular. aberturas. outros territórios-subjetividades. singularidade. derivas. experimentação. vizinhanças. minoridades. estilhaços. fronteiriça. brotamentos. inter(in)venção. co-criação. re-existências plurais. não-ser. rebelião. fim ao juízo de deus. corpo não aguenta mais. usos menores. desmedidas. urgências. simbioses. inclassificável. possibilidades menores. in(ventos). corpo-mundo. apostas. passagem. explosão. não-eu. des-razão. sopros de vida. denúncia. fecund-ações. co-evolução. nascimentos. insurgências. contrapelo.

\footnotetext{
${ }^{12}$ Esses conceitos e afetos compõem um exercício de encontros e insurgências de modos de pensar aberturas de leituras e variações com à educação em biologia a partir de pesquisas em gênero-sexualidade-educação em biologia, pelas quais passamos e as quais passam por nós, assim tentamos tecer minúsculas alianças que possam fazer insurgir vibrações nas complexas configurações territoriais. Com isso produzimos um "Manifesto: linhas e maquinações e minorações e biologias e..." (SANTOS; MARTINS, 2020). In: Omitido em virtude da etapa de avaliação pelos pares.
} 


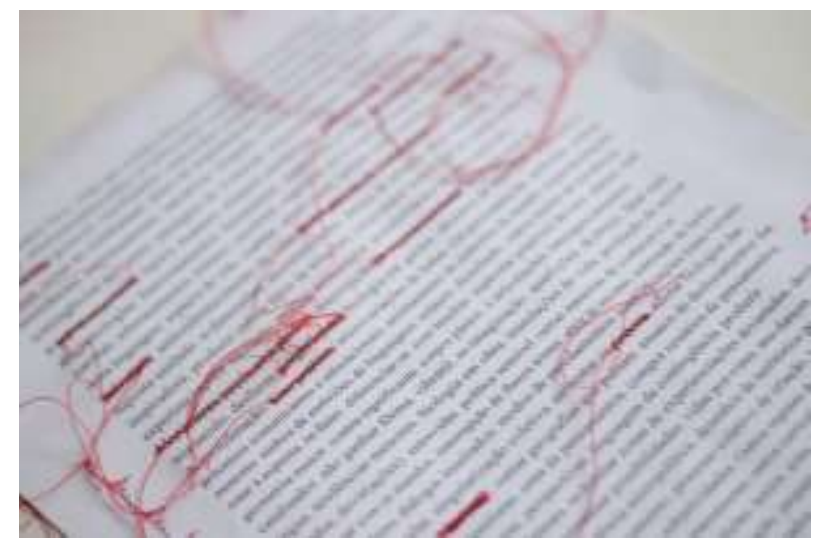

Figura 2: Manifesto - Foto-Autoria: Camila de Sousa Siqueira

raspagem do tne. avesso. desafios. (trans)bordamentos. fazer mundo. virtualidades. abalos. contágios. gen(ética)s. eco-morfo-bio-fisio-e(m)to-embrio-zoo-cito-logias. (in)volução criadora. vulnerabilidades. insurreição. floemas. fugir as molaridades. hibridização. infecção. diferenciação. subjetividades. desejos. fertilidade. microrevolucionária. diferenças. filosofias. rizomática. bagunçar os eédiges. pensar outramente. redes. encantamento. (trans)mutações. transmut-ação. forças heterogen(éticas). outramentos contínuos. acon-teçimentos. carto-grafias possíveis. resistências às biopolíticas. in-tensões. capilar. metamorfoses. misturas. forças de variação. afirmação. Rupturas. corpossibilidades. vibrações. dê-lírios. corpoexperimentação. in-definiçãa. biopotência. bioauto(poiético). auto-re-criação. subtração. devém. entre. meio. riscos. rabiscos. implic-ações. desejante. entranhamentos. crítica. destituída de pretensẽes. inventação.. dissidente. dis-torções. deseonvencional. lampejos. centelhas. trincheiras. fluxos de revides. co-existências. reverberações. ressonâncias. pulsante. ramificações. expressões. imanência. entrelaçamento. narrativas. irrupção. dobras. radículas difusas. contingências moventes. fractal. a-representacional. lapsos. nuances. sinapses semânticas. núpcias. epistemologias. funcionamentos. ferramentas. Reaprender. lutar. matilhas. esburacamentos. mínimo. cacofonia. engendrar novos espaços-tempos. fabricar uma outra linguagem. espaços de vida. coabitar. atentividade. habitar outros territórios. $n$-dimensões. ancestralidades. feixes de relação. ecos-sistemas. co-inspiradora. (re)compor territórios outros. biologia-germe. desfazer o significado.. embriões. ninhos. processos comunicantes e educacionais. aninhamento de embriões de mundo-linguagens. enlaces. dissolução. outros modos de existência. estar à espreita. re-fazer. diferenciar-se. brechas. possíveis devires. alarme vital. não ganhar fôrma. vibrátil. re-imaginação. apari-ções. falar essa língua. tendências menores. biologia em obra. inundações de vida. devir(ações). entrevidas. política sensível. outras maneiras de conhecer e se relacionar com os mundos. interrupção de fluxos tristes. abrir às escutas. diálogos inusitados. enredamentos. comunicações trans-versais. biologia singular. tessituras. compor cenas/cenários de pensamentos. convívios. microfissuras. perspectivas. linguagem da contingência. produzir intercessores. abrir parênteses. re-habitar zonas de experienciações devastadas. Deslocamentos das lógicas habituais. combates. potência micropolítica. desenhos de territórios por vir. esgarçamento. processo coletivo de criação. trans-figuraçãe. desobstrução de subjetividades. e... e... 


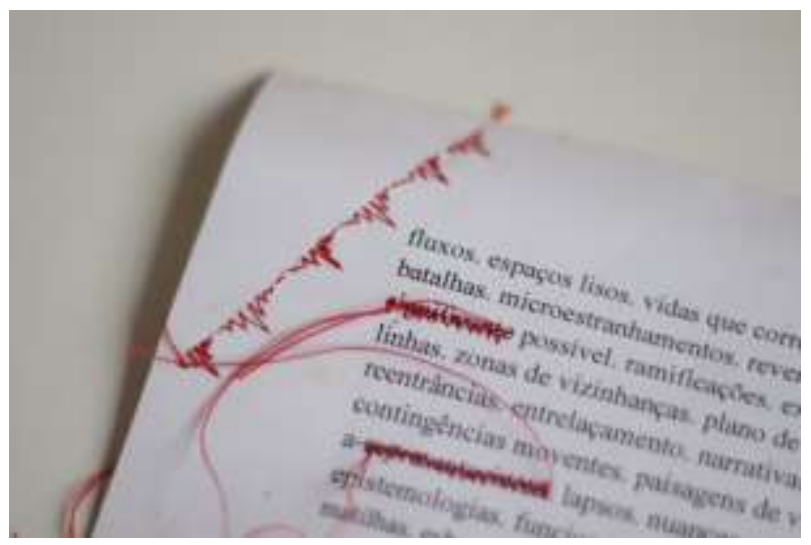

Figura 3: Manifesto - Foto-Autoria: Camila de Sousa Siqueira

\section{Considerações}

A proposta de composição do presente texto se ocupou e acon-teceu com minúsculas alianças com a obra "Kafka: por uma literatura menor"; as produções poéticas de Manoel de Barros; e, os deslocamentos do conceito do menor no campo educacional, acompanhadas por linhas de variação contínuas (por seus usos menores) de um manifesto e insurgências de vibrações-murmúrios nas complexas configurações territoriais em gênero-sexualidadeeducação em biologia.

Consideramos que em textos curriculares da educação em biologia, corpos, gêneros e sexualidades sofrem um enxerto, uma operação, tornando-os maiores ao serem: significados, representados, juizados, organizados, interpretados; e aí, sim, fazendo de alguns irrelevantes, des-im-potentes, (in)significantes. Com um manifesto de menos, estamos subtraindo alguma coisa da educação em biologia para fazer aparecer algo diferente; mas o que sobra? sobra tudo, mas sob novos espaçostempos, com outros territórios híbridos, repletos de reentrâncias, menos significações e incessantes variações contínuas na tentativa de re-encontrar suas potencialidades de vida e de pensamento.

Com isso, continuaremos nos debruçando nas travessuras de mapear linhas a partir de outros movimentos, políticas, gramáticas, epistemologias que fissuram tentativas totalitárias de uso maior nos territórios da educação em biologia.

\section{Inter(in)venções}

BARROS, Manoel. Poesia Completa. São Paulo: Leya, 2010.

BARROS, Manoel. O livro das ignorãças. 1. ed. Rio de Janeiro: Alfaguara, 2016.

DELEUZE, Gilles. Um manifesto de menos. In: DELEUZE, Gilles. Sobre teatro: um manifesto de menos; o esgotado. Tradução de Fátima Saadi, Ovídio de Abreu, Roberto Machado. Rio de Janeiro: Jorge Zahar Ed., 2010. p. 25-64.

DELEUZE, Gilles. A literatura e a vida. In: DELEUZE, Gilles. Crítica e Clínica. Tradução de Peter Pál Pelbart. São Paulo: Editora 34, 2011. p. 11-17.

DELEUZE, Gilles.; GUATTARI, Félix. Kafka: por uma literatura menor. Tradução de Cíntia Vieira da Silva. 1. ed. Belo Horizonte: Autêntica Editora, 2015. 
FOUCAULT, Michel. Microfísica do Poder. Tradução de Roberto Machado. Rio de Janeiro: Edições Graal, 1979.

GALLO, Sílvio. Deleuze \& a Educação. 3. ed. Belo Horizonte: Autêntica Editora, 2016.

HARAWAY, Donna. Raça: doadores universais em uma cultura vampira. Tradução: Sandra Azeredo. In: LESSA, Patrícia.; GALINDO, Dolores. (Org.). Relações multiespécies em rede: feminismos, animalismos e veganismo. Maringá: EDUEM, 2017. p. 47-94.

PARAÍSO, Marlucy Alves.; CALDEIRA, Maria Carolina da Silva. Apresentação. In: PARAÍSO, Marlucy Alves.; CALDEIRA, Maria Carolina da Silva. (Org.). Pesquisas sobre currículos, gêneros e sexualidades. Belo Horizonte: Mazza Edições, 2018. p. 13-21.

RANNIERY, Thiago.; LEMOS, Paula Cunha de. Gênero pode ser uma categoria útil para o ensino de Biologia? In: VILELA, M. L. et al. (Org.). Aqui também tem currículo! Saberes em diálogo no ensino de biologia. Curitiba: Editora Prismas, 2018. ISBN: 978-85- 537-0044-8. p. 65-86.

SANTOS, Sandro Prado. Experiências de pessoas trans - ensino de Biologia. 2018. 289 f. Tese (Doutorado em Educação). Programa de Pós-Graduação em Educação, Universidade Federal de Uberlândia, Uberlândia, 2018.

SANTOS, Sandro Prado; MARTINS, Matheus Moura. Manifesto: linhas e maquinações e minorações e biologias e... Revista Coletiva - Coluna: Educação e diferenças e... n. 15. dezembro/2020.

SANTOS, Sandro Prado; SILVA, Fabrício Aparecido Gomes da.; MARTINS, Matheus Moura. Sexualidades e gêneros e educação em biologia menor e cartografias de suas pequenas redes em livros didáticos - PNLD/2018. Revista Diversidade e Educação, v. 9, número especial, 2021 (no prelo).

\section{Sobre os autores}

Sandro Prado Santos. Doutor em Educação pela Universidade Federal de Uberlândia. Professor Adjunto do curso de Ciências Biológicas do Instituto de Ciências Exatas e Naturais do Pontal (ICENP/UFU), da Universidade Federal de Uberlândia. Vice-Presidente da Associação Brasileira de Ensino de Biologia (SBEnBio), gestão 2019-2021.

E-mail: sandro.santos@ufu.br.

Matheus Moura Martins. Licenciado em Ciências Biológicas pelo Instituto de Ciências Exatas e Naturais do Pontal, campus da Universidade Federal de Uberlândia (UFU). Mestrando em Educação (PPGED/FACED) da Universidade Federal de Uberlândia.

E-mail: matheus.moura@ufu.br.

Fabrício Aparecido Gomes da Silva. Licenciando em Ciências Biológicas pela Universidade Federal de Uberlândia (ICENP-UFU) e Bolsista de Iniciação Científica financiada pelo CNPQ. E-mail: fabricio_apdo@hotmail.com/gomesfabricio1993@gmail.com. 